\title{
Thyroid nodule: not as clear-cut as it seems
}

\author{
Gilbert Bader, MD, ${ }^{a}$ Igor Puzanov, MD, MSCI, FACP, ${ }^{b}$ and Kanishka Chakraborty, MD, \\ FACPa
}

${ }^{a}$ East Tennessee State University, Quillen College of Medicine, Medical Oncology and Hematology, Johnson City, Tennessee; and ${ }^{b}$ Vanderbilt University Medical Center, Division of Hematology-Oncology, Nashville, Tennessee

$\mathrm{B}$ enign etiologies and primary thyroid cancers are the most common causes of incidental thyroid nodules. Clinically evident metastases to the thyroid gland are not common and account for $2 \%-3 \%$ of thyroid cancers, though the incidence of thyroid metastases reaches $24 \%$ in autopsy studies. ${ }^{1}$ The most common clinically detected thyroid metastases originate from renal cell carcinoma (RCC; 48.1\%). ${ }^{2}$ We report here a rare case of a man with clear-cell RCC with late recurrence in the thyroid gland as a solitary metastasis, 13 years after the primary diagnosis. The patient received neo-adjuvant targeted therapy with sunitinib, then underwent thyroidectomy. The surgical margins were positive, and the patient had adjuvant radiation therapy. He is currently on long-term surveillance.

\section{Case presentation and summary}

A 69-year-old man presented to our institution and reported having felt a neck nodule on self-palpation. His past history was significant for stage III clearcell RCC 13 years before the current presentation. At that time, he was treated with left radical nephrectomy. His first recurrence happened 3 years after his first diagnosis, with the development of a mass over his duodenal wall, which required the Whipple procedure. He developed 2 subsequent second primaries of the right kidney, which were managed with radiofrequency ablation (RFA), at 4 and 9 years after initial diagnosis. In addition, he had stage 2 chronic kidney disease and hypertension.

The patient denied weight loss, anorexia, bone pain, hematuria, palpitation, headache, swallowing difficulties, or dysphonia. The results of his physical examination were remarkable for nodularity over the left lateral aspect of the thyroid gland, $4-5 \mathrm{~cm}$ in diameter, hard in consistency, and with no associated cervical adenopathy. An ultrasound showed a 5.1-cm left thyroid nodule. The patient's thyroid stimulating hormone level was normal. The results of a positron-emission tomography scan reveal no extrathyroidal disease (Figure 1). We performed a fine-needle aspiration of the thyroid nodule. The malignant cells displayed clear cytoplasm with oval nuclei and distinct nucleoli. They were positive for CD10, vimentin, EMA (epithelial membrane antigen), PNRA (proximal nephrogenic renal antigen), PAX2, PAX8, and CA9; and negative for TTF-1 (thyroid transcription factor-1; Figure 2). Diagnosis of metastatic clear-cell RCC to the thyroid gland was confirmed.

The patient had good prognosis based on the Memorial Sloan-Kettering Cancer Center (MSKCC) prognostic model: the interval from primary diagnosis to treatment $>1$ year $(13$ years for our patient); Karnofsky performance status $>80 \%$ (100\% denotes normal; $80 \%$, normal activity with effort; some signs or symptoms of disease); a lactate dehydrogenase level $<1.5$ the upper limit of normal (109 U/L for our patient; normal: 140-280 U/L); corrected calcium level of less than the upper limit of normal $(9.7 \mathrm{mg} / \mathrm{dL}$; normal: $8.5-10.2 \mathrm{mg} / \mathrm{dL})$ and a hemoglobin level of greater than or equal to lower limit of normal $(13 \mathrm{~g} / \mathrm{dL}$; normal: $13.5-17.5$ $\mathrm{g} / \mathrm{dL}$ ).

We decided to begin systemic therapy with sunitinib. After 3 months, the size of the nodule had decreased by more than $70 \%$, with resolution of tumor grade activity. Subsequently, the patient underwent total thyroidectomy. The surgical margins were focally positive for carcinoma. He then completed external beam radiation therapy to the thyroid bed. He is currently on long-term clinical and radiological surveillance.

\section{Discussion}

RCC accounts for about $4 \%$ of adult malignancies. ${ }^{3}$ The subtype is clear cell in $80 \%$ of cases. ${ }^{4}$ It is a slow growing malignancy. The median age at diagnosis is 66 years. ${ }^{4}$ The incidence of metastatic RCC is

Accepted for publication May 12, 2015. Correspondence: Kanishka Chakraborty, MD, FACP; chakrabk@mail.etsu.edu. Disclosures: The authors have no disclosures. JCSO 2016;14:45-48. (2016 Frontline Medical Communications. DOI 10.12788/jicso.0184. 

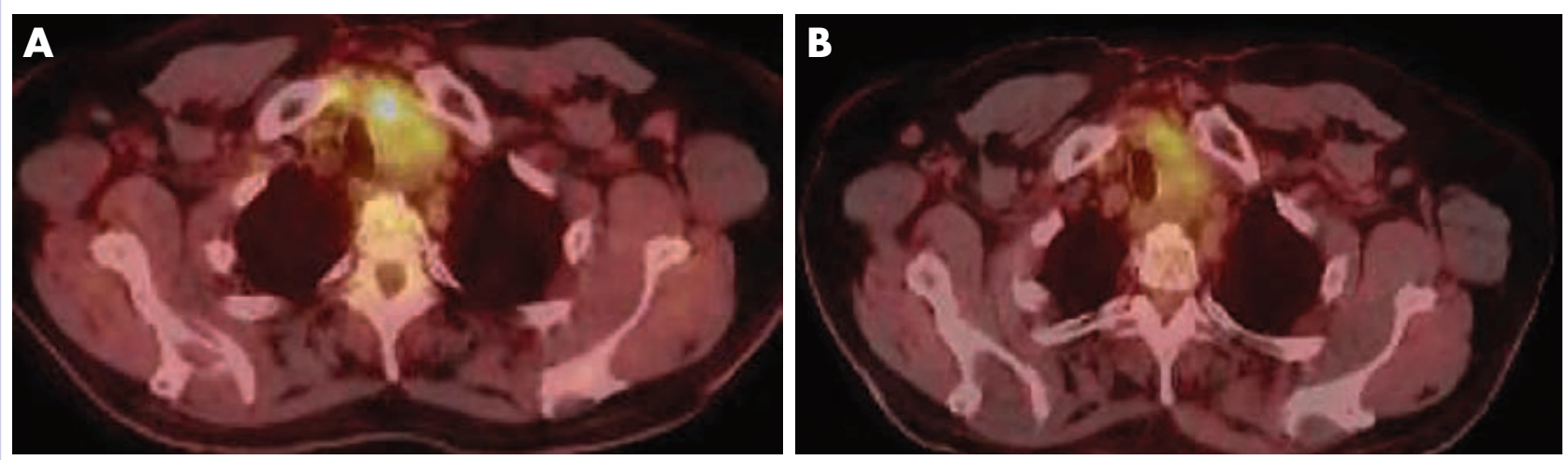

FIGURE 1 Positron-emission tomography images before (A) and after (B) therapy.

increasing secondary to smoking and obesity. Metastases are present at diagnosis in 30\%-40 \% of cases, otherwise they are most likely to occur in the subsequent 3-5 years after initial diagnosis. They most commonly involve the lungs, lymph nodes, bones, liver, and brain. In the absolute majority of cases, they occur in more than 1 site. In metastatic RCC, overall 2-year survival rates in the favorable, intermediate, and poor risk categories are $45 \%, 17 \%$, and 3\%, respectively, based on history of nephrectomy, performance status, hemoglobin, lactate dehydrogenase, calcium, and albumin (MSKCC prognostic model). ${ }^{5}$ In the era of targeted treatment, a newer risk prognostication model with the incorporation of platelet and neutrophil counts further validates MSKCC data. ${ }^{6}$ Newer nomograms ${ }^{7}$ incorporating molecular markers (Ki-67, endothelial VEGFR-1, p53, and so on) have shown more predictive accuracy for survival.

$\mathrm{RCC}$ is resistant to chemotherapy and partially respon- sive to immunotherapy. Thus, treatment of metastatic $\mathrm{RCC}$ is challenging. An extreme minority will respond completely to immunotherapy. Therefore, metastasectomy remains the essential treatment. The overall standard criteria for consideration of metastasectomy have not yet been well established. Contralateral metachronous relapses occur in $0.4 \%-12.9 \%$ of patients, an average 5.2 years after initial surgery. ${ }^{8}$ It is not clear whether they present as metastases or primary tumors. ${ }^{11}$ Multifocality and positive surgical margins were associated with risk of contralateral recurrence. ${ }^{8}$ In patients with a solitary kidney, even minimally invasive surgery may lead to renal failure. RFA must be attempted first, especially for exophytic masses that are $<3 \mathrm{~cm}$ in diameter. ${ }^{9}$ For large tumors or tumors adjacent to critical structures, combined embolization must be performed. It is interesting to note that patients with metachronous contralateral tumors are at a higher risk of developing distant metastases. ${ }^{10}$
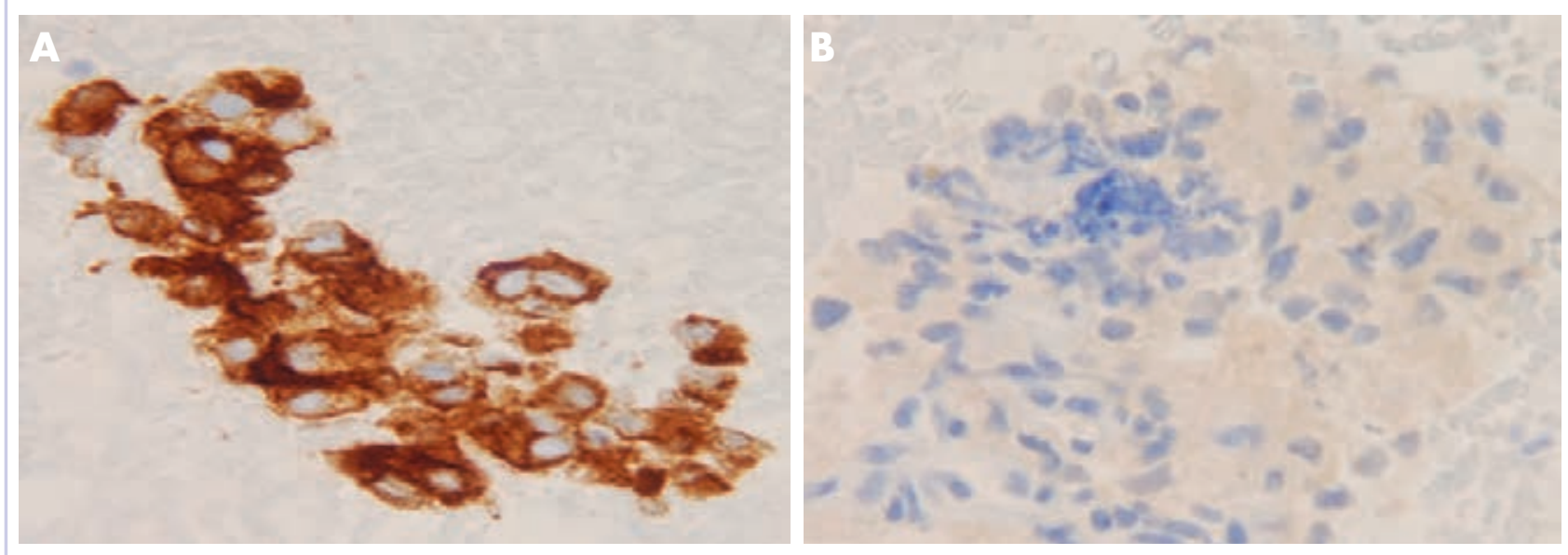

FIGURE 2 Malignant cells from the thyroid nodule displayed clear cytoplasm with oval nuclei and distinct nucleoli and were positive for epithelial membrane antigen (A) and negative for thyroid transcription factor-1 (B). 
TABLE 1 Key studies discussing metastasectomies

Study Patient population

$\begin{array}{ll}\text { Kierney }^{14} & \begin{array}{l}41 \text { patients with solitary } \\ \text { metastases from RCC } \\ \end{array} \\ \begin{array}{l}36 \text { patients had } \\ \text { complete resection }\end{array} \\ \text { Swanson }^{15} & \begin{array}{l}179 \text { patients underwent } \\ \text { resection for solitary metastases } \\ \text { from } \mathrm{RCC}\end{array}\end{array}$

$\mathrm{Alt}^{16}$

$$
\begin{aligned}
& \text { - } 887 \text { patients with } \\
& \text { multiple metastases from } \\
& \text { RCC } \\
& \text { - } 125 \text { patients underwent } \\
& \text { complete resection of all } \\
& \text { metastases } \\
& =257 \text { patients had } \\
& \text { resection of at least } 1 \\
& \text { but not all metastases }
\end{aligned}
$$

\section{Outcomes}

- Survival at 1,3, and 5 years after complete metastatic resection was $77 \%, 59 \%$, and $31 \%$, respectively

- Median survival was 3.4 years

- 5-year survival rate was $29 \%$

- Disease-specific 5-year survival rate for all sites was 19\%

- Median CSS was 4.8 years, overall survival was 4 years after complete resection.

- CSS for patients with incomplete resection was 2.6 years

- CSS for patients who had no resection was 1.1 years

- 5- year survival rate after complete, incomplete, or no resection was $45 \%, 23 \%$, and $8 \%$, respectively
Notes
$-$

Patients with metachronous metastases had better outcomes than those with synchronous metastases (5-year survival rate, $39 \%$ vs $22 \%$ )

Patients benefit from complete resection regardless of timing of metastases

- Even incomplete resection is beneficial

- Survival advantage was evident after complete resection of synchronous as well as metachronous lesion

- This study has extended previous studies results and showed survival benefit after resection of even multiple metastases

CSS, cancer-specific survival; RCC, renal cell carcinoma

Metastases to the thyroid gland are not common. That may be explained by the thyroid rapid arterial flow, which prevents adhesion of tumor emboli, ${ }^{11}$ and by the high content of oxygen and iodine, which inhibit malignant growth. Thus, any thyroid pathology can predispose to metastatic growth by alteration of the thyroid microenvironment. ${ }^{2}$ Thyroid metastases are solitary in $40 \%$ of cases. They are diagnosed 1-19.5 years after nephrectomy in men, and 0.2526.3 years in women. ${ }^{12}$ Clear-cell cytology is not limited to clear-cell RCC. A tumor-directed immunohistochemistry is crucial for diagnosis. If the fine-needle ablation results are inconclusive, then thyroidectomy must be performed. ${ }^{1}$

For solitary metastases that may be surgically resectable, metastasectomy with or without a short course of neoadjuvant VEGF-targeted therapy or tyrosine kinase inhibitor is the mainstay of treatment. Surgery is thought to be the only intervention with cure potential, provided that the disease is limited to the thyroid gland. ${ }^{13}$ In the case series from Mayo Clinic, ${ }^{14}$ survival rates at 1,3 , and 5 years after metastasectomy were 77\%, 59\%, and 31\%, respectively. Data from MD Anderson Cancer Center, Houston, Texas, showed an overall survival of 5 years in $29 \%$ of patients in a group that underwent metastasectomy for solitary lesions, ${ }^{15}$ compared with $<20 \%$ in untreated patients. Surgery is considered palliative if the surgical margins are tumor infiltrated. Radiation therapy may be considered in cases of incomplete metastases removal or local recurrence. Factors affecting survival after thyroidectomy include positive surgical margins, being younger than 70 years, metastases in the contralateral kidney during disease course, and presence of more than 4 thyroid metastases. Median survival after thyroid metastasectomy is 2 years (Table).

In conclusion, thyroid metastases must be included in the differential diagnosis of thyroid nodule, especially in patients with a history of cancer, even decades after initial diagnosis. Thus, we suggest an expedited pathological diagnosis of occult thyroid nodule in individuals with history of RCC.

\section{References}

1. Wood K, Vini L, Harmer C. Metastases to the thyroid gland: the Royal Marsden experience. Eur J Surg Oncol. 2004;30:583-588.

2. Chung AY, Tran Tb, Brumund KT, Weisman RA, Bouvet M.

Metastases to the thyroid: a review of the literature from the last decade. Thyroid. 2012;22:258-268.

3. Siegel R, Ma J, Zou Z, Jemal A, et al. Cancer Statistics 2014. CA Cancer J Clin. 2014;64:9-29.

4. Koul H, Huh JS, Rove KO, et al. Molecular aspects of renal cell carcinoma: a review. Am J Cancer Res. 2011;1:240-254.

5. Motzer RJ, Bacik J, Murphy BA, et al. Interferon-alpha as a comparative treatment for clinical trials of new therapies against advanced renal cell carcinoma. J Clin Oncol. 2002;20:289-296.

6. Choueiri T, Garcia JA, Elson P, et al. Clinical factors associated with outcome in patients with metastatic clear-cell renal cell carcinoma treated with vascular endothelial growth factor-targeted therapy. Cancer. 2007;110:543-550

7. Klatte T, Seligson D, LaRochelle J, et al. Molecular signatures of localized clear cell renal cell carcinoma to predict disease-free 


\section{Case Report}

survival after nephrectomy. Cancer Epidemiol Biomarkers Prev. 2009;18:894-900.

8. Bani-Hani AH, Leibovich BC, Lohse CM, Cheville JC, Zincke $\mathrm{H}$, Blute ML. Associations with contralateral recurrence following nephrectomy for renal cell carcinoma using a cohort of 2,352 patients. J Urol. 2005;173:391-394.

9. Breen DJ, Rutherford EE, Stedman B, et al. Management of renal tumors by image-guided radiofrequency ablation: experience in 105 tumors. Cardiovasc Radiol. 2007;30:936-942.

10. Amano H, Kondo T, Hashimoto Y, et al. Contralateral metachronous tumor occurrence is more frequently associated with distant metastases or postoperative intrarenal recurrence in renal cell carcinoma patients. Int J Urol. 2010;17:615-622.

11. Beahrs OH, Ginsberg RL, Miller GE. Metastatic hypernephroma of the thyroid gland. Proc Mayo Clin. 1985;28:205-216.
12. Sindoni A, Rizzo M, Tuccari G, et al. Thyroid metastases from renal cell carcinoma: review of the literature. Sci World J. 2010;10:590-602.

13. Iesalnieks I, Winter $H, B$ areck $E$, et al.Thyroid metastases of renal cell carcinoma: clinical course in 45 patients undergoing surgery. Assessment of factors affecting patients survival. Thyroid. 2008; $18: 615-624$

14. Kierney PC, Van Heerden JA, Segura JW, Weaver AL. Surgeon's role in the management of solitary renal cell carcinoma metastases occurring subsequent to initial curative nephrectomy: an institutional review. Ann Surg Oncol. 1994;1:345-352.

15. Swanson DA. Surgery for metastases of renal cell carcinoma. Scand J Surg. 2004;93:150-155.

16. Alt AL, Boorjian SA, Lohse CM, Costello BA, Leibovich BC, Blute ML. Survival after complete surgical resection of multiple metastases from renal cell carcinoma. Cancer. 2011;117:2873-2882. 